\title{
STRATEGI PELAYANAN GEMBALA SIDANG DALAM PEMBINAAN WARGA GEREJA BAGI KEDEWASAAN ROHANI JEMAAT
}

\author{
Hisikia Gulo ${ }^{1^{*}}$ \\ ${ }^{1}$ Sekolah Tinggi Teologi Soteria Purwokerto \\ *Email: hiskiagulo27@gmail.com
}

\section{THE SERVICE STRATEGY OF CHURCH SHADHERD IN COACHIN}

\begin{abstract}
The formation of church members is the full responsibility of the pastor as spiritual leaders for God's congregation. Duties and responsibilities in carrying out the Great Commission of the Lord Jesus (Matthew 28:19-20). This study aims to describe the understanding of the pastors in carrying out their pastoral duties as a guide for the spiritual maturity of the congregation so that the members of the congregation will be more in the image and likeness of Jesus Christ. The research method was carried out by qualitative methods with a literature study approach. The results showed : that the pastor and church members go hand in hand or synergize in guiding, directing, guiding and caring in the context of growing together in Jesus Christ with the humility of a spiritual leader, or the character of the shepherding as Jesus gave a true example.
\end{abstract}

\section{Keywords: Pastor, Community Development, Spiritual Maturity}

Abstrak: Pembinaan warga gereja merupakan tanggung jawab penuh gembala sidang sebagai pemimpin rohani bagi jemaat Tuhan. Tugas dan tanggung jawab dalam rangka menjalankan Amanat Agung Tuhan Yesus (Mat. 28:19-20). Penelitian ini bertujuan untuk mendeskripsikan pemahaman para gembala sidang dalam menjalankan tugas penggembalaannya sebagai pembimbing bagi kedewasaan rohani jemaat sehingga warga jemaat semakin segambar dan serupa Yesus Kristus.berhubungan dengan pembinaan wakga gerej maka Mucul beberapa pertaanya sebagai berikut: 1) Bagaimanakah Hakikat pembinaan warga gereja? 2) Apakah tujuan Pembinaan warga gereja, 3) apakah pentingnya pembinaa warga gereja. Untuk itu Metode penelitian dilakukan dengan metode kualitatif dengan pendekatan studi pustaka. Hasil penelitian menunjukkan bahwa gembala sidang dan warga gereja berjalan bersamaan atau sinergi dalam membimbing, mengarahkan, menuntun dan merawat dalam konteks bertumbuh bersama-sama di dalam Yesus Kristus dengan penuh kerendahan hati dari seorang pemimpin rohani, atau karakter penggembalaan seperti yang Yesus berikan teladan sejati.

\section{Kata Kunci: Gembala Sidang, Pembinaan Warga Gereja, Kedewasaan Rohani}

\section{PENDAHULUAN}

Pembinaan warga gereja merupakan tanggung jawab penuh gembala sidang sebagai pemimpin rohani bagi jemaat Tuhan. Pembinaan warga gereja adalah tanggung jawab dalam menjalankan misi-Nya Tuhan Yesus datang kedunia (Mat. 28:19-20). Maka misi Agung Yesus Kristus hendak di kerjakan oleh gembala sidang sebagai pemimpin dari sebuah gereja, maka gembala sidang harus berpikir dan bertindak secara strategis. Dalam rangka menjadikan semua orang menjadi murid Yesus, pemberita Injil, pembaptisan

\footnotetext{
1Junihot M. Simanjuntak, "Implikasi Konsep dan Desain Kurikulum dalam Tugas Pembinaan
}

dalam nama Bapa, Anak dan Roh Kudus, serta pengajaran agar orang percaya mengikuti dan mempraktekkan ajaran Yesus Kristus. ${ }^{1}$ Maka gembala sidang memiliki tanggung jawab yang sangat penting, yaitu pembinaan kepada seluruh warga gerejanya. Akan tetapi ada sebagian gembala sidang atau pemimpin rohani bagi jemaat yang tidak efektif melaksanakan tugas penggembalaan sebagai mana mestinya pemimpin rohani dalam membina warga gereja. Seperti dijelaskan Hendi \& Syelin Umur dalam penelitiannya

Warga Jemaat," Jurnal Jaffray 12, No. 2 (2014): 251-72. 
bahwa adanya kepincangan ketika seorang gembala sidangmenekankan kebenaran namun ternyata tidak teraplikasi di dalam kehidupan pribadinya dan pada akhirnya menjadi contoh buruk bagi umat dan orang yang belum percaya pada Kristus. ${ }^{2}$ Hal tersebut banyak dijumpai dalam ladang pelayanan sehingga gambaran pelayanan yang ideal manjadi kabur.

Jika gembala sidang sebagai pemimpin rohani bagi warga gereja melalaikan tanggung jawab penggembalaan, maka jangan menyesal jika iman anggota jemaat tidak mengalami pertumbuhan yang signifikan, dan menjadi mangsa empuk bagi "serigala-serigala ganan" di sekitarnya. ${ }^{3}$ Dalam melaksanakan pembinaan warga gereja secara efesien gembala sidang harus melakukan analis yang akurat sehingga mampu menetapkan langkah strategis pelayanan yang dilakukan dengan mengetahui kebutuhan rohani jemaat, merancangkan program yang sesuai dengan tingkat dan kedewasaan rohani jemaat, serta juga memperhatikan keragaman anggota jemaat. ${ }^{4}$ Warga gereja dewasa, sangat membutuhkan pembinaan, karena merekalah yang akan mengajarkan kebenaran-kebenaran firman Tuhan kepada anak-anak mereka atau generasi muda di bawahnya, agar mewarisi iman dan teladan Yesus Kristus.

Ada banyak faktor pembinaan warga gereja yang dapat membuat seorang gembala sidang sebagai pemimpin rohani berhasil. Fibry Jati Nugroho mengatakan gereja yang

\footnotetext{
${ }^{2}$ Hendi \& Syelin Umur, "Strategi Pelayanan Pastoral bagi Kaum Awam menurut Bapa Gereja Gregorius Agung," Fidei: Jurnal Teologi Sistematika dan Praktika 3, no. 1 (2020): 37-61.

3 Jeny Marlin, "Pembinaan Warga Gereja Dewasa menurut Surat Efesus 4: 11-16," Missio Ecclesiae 5, no. 1 (2016): 22-34.

${ }^{4}$ Purim Marbun, "Strategi dan Model

Pembinaan Rohani untuk Pendewasaan Iman Jemaat," Jurnal IImiah Religiosity Entity Humanity (JIREH) 2, no. 2 (2020): 151-69, https://doi.org/10.37364/jireh.v2i2.42.

5 Fibry Jati Nugroho, "Pendampingan Pastoral Holistik: Sebuah Usulan Konseptual
} 18 | Excelsis Deo: Jurnal Teologi, Misiologi dan Pendidikan kuat terbentuk dari jemaat yang kuat. Gereja yang yang mempunyai kekuatan didapat dari pembinaan warganya yang secara aktif menyentuh keseluruhan kehidupan warga gerejanya. $^{5}$ Sementara Dwi Ariefin menekankan pentingnya persekutuan berdasarkan kasih, positif dan konstruktif diadakan secara rutin untuk membina dan memperkuat kesatuan dalam kemajemukan dalam gereja (unity in diversity). ${ }^{6}$ Pada prinsipnya, seorang gembala sidang harus dapat memberikan panutan atau keteladanan dalam kepemimpinan. Keteladanan merupakan aspek penting dalam kepemimpinan seorang gembala sidang. Memberikan teladan artinya, seorang pemimpin harus memulai dari hidupnya untuk memimpin, sehingga apa yang dilakukan tidak sekedar dibuat-buat. ${ }^{7}$ Dalam hal inilah dibutuhkan kerendahan hati seorang pemimpin rohani, atau karakter penggembalaan seperti yang Yesus berikan teladan sejati.

Pembinaan warga gereja yang menekankan strategis memang bukanlah suatu hal yang baru dalam pembahasan teologi pastoral atau kepemimpinan Kristen. Purim Marbun menekankan dalam penelitiannya tentang strategi dan model pembinaan rohani untuk pendewasaan iman jemaat bahwa pembinaan warga gereja merupakan tanggung jawab pemimpin rohani atau pendeta jemaat. ${ }^{8}$ Seorang gembala sidang atau pendeta adalah pribadi yang melayani tanpa

Pembinaan Warga Gereja," Evangelikal: Jurnal Teologi Injili dan Pembinaan Warga Jemaat 1, No. 2 (2017): 139-54, https://doi.org/10.46445/ejti.v1i2.71.

${ }^{6}$ Dwi Ariefin, "Peran Serta Menjaga Kemajemukan Bangsa Dengan Pembinaan Warga Gereja," Pasca: Jurnal Teologi dan Pendidikan Agama Kristen 15, No. 2 (2019): 33-38.

${ }^{7}$ Dorus Dolfinus Buinei, "Menerapkan Kualifikasi Kepemimpinan Hamba menurut Injil Markus bagi Gembala Sidang GPdl Wilayah Waropen Barat , Papua," Epigraphie: Jurnal Teologi dan Pelayanan Kristiani 4, No. 1 (2020): 18-30.

8 Ibid., 168. 
mempertimbangkan harga diri seorang pemimpin rohani. Pokok inilah yang menjadi fokus dalam penelitian ini, bagaimana seorang gembala sidang memahami panggilannya secara hakiki untuk melayani, dalam situasi apa pun. Penelitian ini bertujuan untuk mendeskripsikan pemahaman gembala sidang dalam menjalankan tugas penggembalaannya sebagai pembimbing bagi jemaat tentunya untuk mendewasakan iman seseorang di dalam Yesus Kristus. Itulah sebabnya, pembahasan ini memiliki tujuan untuk terus melihat berbagai masalah yang berkaitan dengan situasi dan kondisi pembinaan warga gereja yang hanya sepihak atau gembala sidang menekankan kebenaran tetapi tidak mengaplikasikan dalam kehidupan sehar-hari. Dan melalui tulisan ini membuka wawasan yang baru bagi gembala sidang dan warga gereja untuk mengaplikasikan kebenaran firman Tuhan agar dapat terus berakar, bertumbuh dan berbuah sehingga semakin serupa dan segambar didalam Yesus Kristus.

\section{METODE}

Dalam penelitian ini, penulis menggunakan metode kualitatif dengan pendektan deskriptif literature. ${ }^{9}$ Pendekatan deskriptif literature adalah teknik pengumpulan data berdasarkan dari kajian pustaka sebagai bahan pendukung perumusan teori. Kemudian penulis berinteraksi dengan teks-teks Alkitab berkaitan dengan pembahasan penulis. Konsep ini terdiri atas sebuah ide utama dan beberapa ide pendukung.

\section{PEMBAHASAN}

\section{Hakikat Pembinaan Warga Gereja}

Dalam pembinaan warga gereja istilah yang dipakai di antaranya pembinaan iman, pembinaan warga gereja, pembinaan jemaat, dan lain sebagainya. Istilah ini hendak menggambarkan kegiatan yang dilakukan oleh gereja dalam hal ini pendeta atau gembala menolong jemaat agar bertumbuh dalam pengenalan Yesus Kristus sebagai Tuhan dan Juruselamat. ${ }^{10}$ Maka pembinaan warga gereja adalah suatu tindakan atau aktivitas pelayanan penggembalaan yang dilakukan terus-menerus berpusat pada Kristus dan berdasarkan firman Allah, dan merupakan proses untuk membangun hubungan yang intim antara warga gereja dengan Firman Tuhan melalui pembimbingan dan mendewasakan orang percaya di dalam menikmati karya penyelamatan Allah didalam Yesus Kristus.

\section{Tujuan Pembinaan Warga Gereja}

Pembinaan warga gereja bertujuan agar jemaat menjadi pemimpin bagi sesama dalam mengajak jemaat untuk ikut Yesus Kristus. Dan memampukkan warga jemaat menjadi alat kesaksian serta menjadi mediator/reflector berkat Allah kepada sesama (Keluarga, Gereja, dan Masyarakat). Menurut Junihot $M$. Simanjutak dalam tulisannya mengatakan bahwa: Pembinaan jemaat adalah untuk memperlengkapi orang-orang kudus bagi pekerjaan pelayanan, bagi pembangunan tubuh Kristus (Ef. 4:12) membelajarkan orang dewasa seumur hidup sesuai dengan kepenuhan Kristus (Ef. 4:13). Pembinaan warga jemaat di lakukan agar setiap orang dewasa menjadi bagian yang integral dalam seluruh tubuh yang rapi tersusun dan diikat menjadi satu oleh pelayanan bagiannya, sesuai dengan kadar pekerjaan tiap-tiap anggota menerima pertumbuhannya dan membangun dirinya dalam kasih (Ef. 4:16). ${ }^{11}$

Dalam pembinaan warga gereja (mengajarkan warga jemaat untuk ikut Yesus, Mat. 28:16-20). Dan misi Agung Yesus Kristus banyak orang mengenal berita atau kabar tentang Injil keselamatan. Pembinaan

\footnotetext{
10 lbid., 154.

${ }^{11}$ Ibid., 257-278.
} 
bagi warga gereja perlu ditekankan tentang bagaimana seorang gembala sidang mendampingi, teladan, kepedulian, kehadiran, peduli, mengasihi-tidak menghakimi. Dan pada prinsipnya melakukan seperti apa yang Tuhan Yesus sudah kerjakan dalam menyelamatkan dan melayani setiap umat manusia. Pembinaan terhadap warga gereja merupakan tugas utama gembala sidang. Kemampuan pembinaan merupakan kriteria yang melaluinya semua kegiatan, termasuk di dalamnya berbicara di depan umum terukur. Pembinaan merupakan sikap saling membangun di antara jemaat Tuhan. ${ }^{12}$ Seorang pemimpin harus dewasa rohani dan mengabdikan diri secara totalitas dihadapan Tuhan. Yang dapat meyakinkan pertumbuhan kedewasaan rohaninya dan yakin akan panggilan Tuhan sebagai hamba Tuhan yang melayani Dia. Dimana Tuhan telah memberikan kepercayaan serta menyerahkan tugas untuk memberitakan injil dan membawa jiwa-jiwa kepada Kristus, dengan pimpinan Roh Kudus. ${ }^{13}$

Dalam pelaksanaan pembinaan warga gereja secara berkesinambungan, terusmenerus, dalam jangka pendek, menengah, dan panjang untuk menghasilkan calon murid, murid, pelatih, dan pemimpin, sehingga banyak warga gereja tidak diperlengkapi dengan kemampuan yang mereka butuhkan ketika mereka berdiskusi dengan anggota masyarakat yang belum diselamatkan, maka banyak warga gereja yang tidak mampu

${ }^{12}$ Susanto Dwiraharjo, "Konstruksi Teologis Gereja Digital: Sebuah Refleksi Biblis Ibadah Online di Masa Pandemi Covid-19," Epigraphe: Jurnal Teologi Dan Pelayanan Kristiani 4, no. 1 (2020): 1-17.

${ }^{13}$ Susana Endang Srisusiani, "Kajian Teologis Pertumbuhan Rohani dan Kepemimpinan yang Menghamba berdasarkan Yehezkiel 22:30," Geneva: Jurnal Teologi dan Pendidikan Agama Kristen 2, No. 2 (2020): 83-91.

${ }^{14}$ Ngendam Sembiring, "Mengatasi Degradasi Moral Melalui Pembinaan Warga Gereja," Illuminate: Jurnal Teologi dan Pendidikan Kristiani 1, no. 1 (2018): 22-42.

20 | Excelsis Deo: Jurnal Teologi, Misiologi dan Pendidikan memengaruhi anggota mayarakat. ${ }^{14}$ Maka, pembinaan warga gereja adalah guna untuk mempersiapkan semua warga jemaat agar memiliki pemahaman yang penuh tanggung dalam iman kepada Yesus Kristus. Kehidupan yang penuh tanggung jawab utuh kepada Yesus Kristus, kepada sesama dan juga kepada diri sendiri.

\section{Pentingnya Pembinaan Warga Gereja}

Pembinaan warga gereja begitu sangat esensial dalam memenuhi kebutuhan dasar penggembalaan gereja. Bagi gembala sidang memimpin orang tidaklah sederhana dan mudah, karena seorang pemimpin rohani itu tidak hanya bertanggung jawab pada dirinya sendiri tetapi juga kepada banyak orang yang dipimpi. ${ }^{15}$ Menurut Telaumbanua gembala sidang adalah seorang pemimpin yang bertanggung jawab untuk melakukan tugas penggembalaan yang selalu erat kaitannya dengan pertumbuhan kerohanian jemaat. ${ }^{16}$ Maka gembala sidang bertanggung jawab bagi warga gereja untuk membawa mereka, bertumbuh ke arah Kristus yang adalah kepala gereja (Ef. 4:15).

Seorang pelayanan bertanggung jawab dalam pembimbingan kepada keselamatan harus terlebih dahulu menyerahkan hidup dalam kebenaran dan menjauhi dosa. ${ }^{17}$ Sebab hanya energi dari Allah yang dapat membawa kebenaran Firman-Nya kepada setiap hati manusia. ${ }^{18}$ Pelayanan penggembalaan adalah sebuah kepercayaan dan anugerah dari Allah.

${ }^{15}$ Indro Puspito, "Yesus sebagai Model Gembala Sejati dan Relasinya terhadap Gembala Sebagai Pendidik," Excelsis Deo: Jurnal Teologi, Misiologi dan Pendidikan 4, No. 2 (2020): 87-107.

${ }^{16}$ Arozatulo Telaumbanua, "Peran Gembala Sidang sebagai Pendidik dalam Pertumbuhan Rohani Jemaat," Fidei: Jurnal Teologi Sistematika dan Praktika 2, No. 2 (2019): 362-87, https://doi.org/10.34081/fidei.v2i2.45.

${ }^{17}$ Gregorius The Great, The Book of Pastoral Rule (New York: Vladimir's Seminary Press, 2007), .

18 Anthony M. Coniaris, Confronting and Controlling Thoughts According to the Fathers of 
Oleh sebab itu, kepercayaan tersebut harus dijaga dengan baik oleh seorang gembala sidang dengan cara menjalankan pelayanan penggembalaan dengan benar yang bertujuan menuntun setiap jiwa yang haus menuju air kehidupan yaitu Kristus dan menyatakan bahwa segala perbuatan dosa bertentangan dengan kehendak Allah. ${ }^{19}$ Jadi, pembinaan warga gereja sangat esensial karena menolong warga gereja bertumbuh dalam iman menuju kepada kedewasaan penuh di dalam Kristus.

\section{Pendekatan kepada Warga Jemaat}

Proses pendekatan bagi warga jemaat memang setiap gembala sidang menggunakan berbagai metode pendekatan. Dalam konteks gereja pembinaan warga gereja seharusnya berlangsung melalui empat jalur "urat nadi" gereja, yaitu: ibadah, persekutuan, pengajaran, dan pelayanan. Dengan demikian penulis akan membahas satu persatu bagian diatas sehingga pembinaan warga gereja semakin maksimal dan semakin mudah bagi setiap gembala sidang dalam pembimbingan dan pendewasaan rohani jemaat.

\section{Ibadah}

Ibadah merupakan hal yang prinsip dalam kehidupan orang percaya. Ibadah merupakan ungkapan iman orang percaya dalam bentuk ritual dan liturgi. Namun ibadah juga dapat dieks- presikan dalam banyak hal. ${ }^{20}$ Waktu yang digunakan dalam ibadah merupakan suatu kesempatan yang indah karena saat itu merupakan suatu waktu untuk berbicara kepada Tuhan, dan merasakan hadirat Tuhan. Orang Kristen bebas

the Philokalia (Minneapolis: Light and Life Publishing, 2004), 76.

${ }^{19} \mathrm{Hendi} \&$ Syelin Umur, "Strategi Pelayanan Pastoral Bagi Kaum Awam Menurut Bapa Gereja Gregorius Agung," Fidei: Jurnal Teologi Sistematika dan Praktika 3, No. 1 (2020): 37-61, https://doi.org/10.34081/fidei.v3i1.68.

20 Sabariah Zega, "Refleksi Teologis tentang Makna Ibadah yang Sejati," Voice of HAMI: memberikan pujian untuk Tuhan dan menyatakan sebesar apa kasih Tuhan itu dalam hidup umat-Nya. Melalui ibadah juga Tuhan dapat berbicara kepada umat-Nya lewat Firman yang menjadi makanan rohani dalam hidup orang percaya dan setia kepada Tuhan. ${ }^{21}$

Ibadah adalah perbuatan menyatakan bakti kepada Allah yang didasari dengan ketaatan, mengerjakan pekerjaan Tuhan dan menjauhi larangan-Nya. Senada dengan yang dikatakan oleh Lucyana Henny bahwa ibadah adalah "perbuatan untuk menyatakan bakti kepada Allah, yang didasari ketaatan mengerjakan perintah-Nya dan menjauhi larangan-Nya." Ibadah ialah aneka tindakan dan sikap yang menghargai dan menghormati kelayakan Allah semesta langit dan bumi yang agung. Jadi, ibadah berpusat kepada Allah dan bukan pada manusia. ${ }^{22}$

Oleh sebab itu, ibadah harus rutin dilakukan untuk kemuliaan bagi nama Tuhan sebab ibadah membuat umat lebih dekat dengan Tuhan dan merasakan hadirat Tuhan dalam kehidupan sehari-hari. Persekutuan orang-orang percaya merupakan sebuah pengaruh besar bagi lingkungan di mana umat itu berada, sebab persekutuan itu adalah sebuah kegiatan untuk menyembah Tuhan dan beribadah. $^{23}$ Dengan demikian dapat dimengerti bahwa ibadah adalah sebuah tindakan untuk menghargai dan menghormati Allah di tempat yang mahatinggi, dan sebuah persekutuan antara Allah dan manusia dalam hadirat Roh Kudus melalui syafaat Yesus Kristus. ${ }^{24}$ Maka menyembah Allah dengan roh dan kebenaran itu adalah penyembahan yang tidak dibatasi oleh ruang dan waktu. Maka

Jurnal Teologi dan Pendidikan Agama Kristen 3, No. 1 (2020): 28-38.

21 John Chysostom, The Christian Priesthood (New York: Vladimir's Seminary Press, 1984), 55.

${ }^{22}$ Lucyana Henny, "Konsep Ibadah yang Benar dalam Alkitab," Excelsis Deo: Jurnal Teologi, Misiologi dan Pendidikan 4, No. 1 (2020): 73-88. 23 Ibid., 34. 24 Ibid., 6. 
Ibadah suatu persembahan hidup manusia dengan Allah secara pribadi dalam ketundukan dan penyembahan. ${ }^{25}$ Jadi, ibadah yang benar adalah pelayanan kepada Allah dengan mempersembahkan seluruh aspek tubuh, jiwa dan roh dengan berbagai tindakan dan sikap penuh hormat dan puja, ketundukan, serta ketaatan dengan penuh ucapan syukur kepada Allah.

\section{Persekutuan}

Dalam persekutuan segala sesuatu di dasarkan pada hanya penebusan Kristus. Persekutuan orang beriman selalu mengarahkan semua orang untuk menceritakan cintak kasih Kristus bagi sesama. Persekutuan membawa kehangatan kepada orang-orang di dalamnya. Memang persekutuan yang sejati adalah persekutuan yang bertumbuh mengarahkan diri semakin hari semakin serupa dan segambar dengan Yesus Kristus. Gembala sidang mengajak dan memfasilitas setiap warga jemaat untuk selalu bersekutu supaya setiap orang semakin bertumbuh dalam pengenalan akan Yesus Kristus. Maka dalam persekutuan orang percaya tentunya akan mengajarkan tentang nilai-nilai kehidupan seperti yang Allah kehendaki. Latih mengatakan bertekun dalam pengajaran dan persekutuan merupakan kebiasaan jemaat mula-mula yang membuat mereka mengalami pertumbuhan dalam kualitas dan kuantitas iman seseorang (Kis. $2: 42){ }^{26}$

Berdasarkan pola hidup gereja mulamula, persekutuan atau pertemuan yang dilakukan oleh orang beriman pada saat itu pun selalu diisi dengan pengajaran Firman Tuhan.

${ }^{25}$ Alexander Stevanus Lukuhay, "Analisis Teologis Mengenai Beribadah di Rumah di Tengah Pandemi Covid-19 di Indonesia," Visio Dei: Jurnal Teologi Kristen 2, No. 1 (2020): 43-61.

${ }^{26}$ Helen Farida Latif, "Pengaruh Pengajaran dan Persekutuan terhadap Tingkat Pertumbuhan Rohani Anak dan Remaja," Epigraphe: Jurnal Teologi dan Pelayanan Kristiani 1, No. 2 (2017): 119-38.

22 | Excelsis Deo: Jurnal Teologi, Misiologi dan Pendidikan
Putra menjelaskan bahwa: Orang percaya secara nyata memperlihatkan kesatuan mereka dalam Yesus Kristus di dalam pelayanan ibadah, di mana mereka disebut saudara satu sama lain. Persekutuan adalah mereka secara sukarela dan secara terus-menerus bersatu dalam ibadah, dalam makanan, saling berbagi dalam segala apa pun yang mereka miliki untuk hal inilah mereka disebut bersaudara satu sama lain. ${ }^{27}$

Firman Tuhan yang dibagikan disana menjadi dasar bagi mereka mengasihi dalam kasih persaudaraan. Maka untuk itu setiap warga jemaat memang tidak bisa lepas atau menjauhkan diri dari persekutuan atau pertemuan orang percaya. Sebab karakter setiap orang akan semakin bertumbuh dalam persekutuan. Hal ini karena pengenalan seseorang akan Allah semakin baik. Setiap manusia ditakdirkan untuk hidup secara sosial, dan tanpa bergaul secara sosial manusia tidak dapat hidup dengan baik. Karena itu manusia harus membangun relasi dengan baik terutama sebagai hamba Tuhan yang tidak lepas dari lingkup sosial sebagai usaha untuk mendidik orang di dalam gereja, melayani manusia dan juga mengabarkan Injil kepada sesama. ${ }^{28}$

Hal ini mengingatkan dan menyadarkan setiap orang percaya bahwa sungguh betapa pentingnya nilai sebuah persekutuan. Akan tetapi kesatuan dalam kebenaran Firman, dalam keberimanan kepada Kristus dan dalam persekutuan dengan Roh Kudus. Oleh sebab itu di perlukan kedewasaan rohani dan kerendahan hati dalam hidup

\footnotetext{
${ }^{27}$ Adi Putra, "Hakikat Pertumbuhan Gereja Berdasarkan Kisah Para Rasul 2: 41-47," Bia': Jurnal Teologi dan Pendidikan Kristen Kontekstual 3, no. 2 (2020): 262-81.

${ }^{28}$ Anton Siswanto, "Hamba Tuhan dan Seni Memberi (Sebuah Tinjauan Biblika berdasarkan Studi Perjanjian Baru)," Excelsis Deo: Jurnal Teologi, Misiologi dan Pendidikan 4, no. 1 (2020): 19-34.
} 
persekutuan orang percaya. $^{29}$ Dengan demikian persekutuan pun bukan hanya membawa orang percaya dekat dengan sesama, tetapi membawa dia relasi dekat dengan Allah, taat dan kuat dalam mengikuti setiap pimpinan Tuhan.

\section{Pengajaran}

Dalam membina warga gereja, tugas gembala sidang adalah memperlengkapi dan mengajar warga jemaat untuk tetap setia kepada Tuhan dan menjalankan perintah-Nya. Pelayanan pembinaan dan pengajaran kepada warga gereja tidaklah cukup diberikan hanya sekali, tetapi harus secara berkelanjutan. ${ }^{30}$ Artinya seorang gembala sidang memberi makan, memberi makan dalam konteks penggembalaan jemaat adalah berbicara tentang mengajar Firman kebenaran dan mendidik mereka melakukan sesuai kehendak Allah. ${ }^{31}$ Tugas seorang gembala sidang dalam memberitakan Injil sangat penting dan memberi pengaruh yang signifikasn bagi kedewasaan rohani jemaat karena apa yang disampaikan oleh gembala sidang dalam khotbah tidak akan lepas dari bagaimana kuasa Tuhan yang bekerja dan terjadi dalam kehidupan orang percaya. $^{32}$ Maka dalam pengajaran tersebut terus berkesinambungan yang diberikan kepada orang beriman sepanjang hidupnya. Kebenaran tentang Allah tidak dapat dibantah oleh siapa pun karena Dia sendiri yang telah menyatakannya kepada manusia.

Dalam hal ini juga Roh Kudus turut mengambil peran dalam memberi pengajaran tentang Allah dan ciptaan-Nya. ${ }^{33}$ Hal ini berarti pengajaran Tuhan Yesus menjadi

${ }^{29}$ St. Maximus the Confessor, The Ascetic Life the Four Centuries on Charity (Longmans: Green and co, 1995), 27.

${ }^{30}$ lbid., 28.

31 lbid., 99.

32 Ibid., 270.

33 Hendi, Formasi Rohani: Fondasi, Purifikasi, \& Deifikasi (Yogyakarta: LeutikaPrio, 2019), 292. sangat penting di dalam kehidupan orang percaya. Sebab itu orang percaya perdana juga bertekun di dalam pengajaran para rasul (Kis. 2:42) yang meneruskan pengajaran Yesus (Mat. 28:16-20). Tuhan Yesus pernah mengajarkan perumpamaan penabur kepara murid-murid-Nya (Mat. 13:10-23). Yesus mengajarkan dan para pendengar tentu mendengar, melihat, berpikir, merasakan apa yang diajarkan oleh Yesus Kristus. ${ }^{34}$ Gembala sidang sebagai pendidik harus mampu menjadi teladan bagi jemaat sebagai murid yang diajar, dididik dan dibimbing. Dorce Sondopen menjelaskan bahwa: "Percontohan" di mana (Yoh. 13: 15) berkata: "Aku telah memberikan suatu teladan kepada kamu". Yesus memperlihatkan cara hidup-Nya: berdoa, menggunakan Alkitab, memenangkan jiwa, mengajar dengan wajar, dan segalanya. Hal itu dilakukan dengan harapan dapat menjadi teladan bagi para murid dan orang lain. ${ }^{35}$ Gembala sidang wajib hidup seperti teladan Yesus. Yesus Kristus dalam pelayanan-Nya didunia memberikan keteladanan bagi seorang gembala yang baik di mana gembala yang baik adalah gembala yang merawat atau memelihara kawanan domba Allah dengan sepenuh hati bahkan rela mengorbankan nyawa-Nya demi dombadomba-Nya (Yoh. 10:11). ${ }^{36}$ Tugas pembinaan warga gereja bagi gembala sidang merupakan mandat yang di percayakan oleh Tuhan untuk di laksanakan sesuai dengan kehendak dan keinginan Allah sendiri.

\section{Pelayanan}

Pelayan adalah seorang hamba Kristus, yang sadar bahwa hidupnya adalah milik Kristus

34 Ibid., 366.

35 Dorce Sondopen, "Relasi Antara Penginjilan dan Pemuridan untuk Pertumbuhan Gereja," Excelsis Deo: Jurnal Teologi, Misiologi dan Pendidikan 4, No. 1 (2019): 95-105.

36 lbid., 104. 
oleh karena Yesus Kristus telah mati baginya dan menyelamatkan hidupnya. Dia berkomitmen kepada satu tuan, yaitu Kristus. Ia memiliki ketaatan penuh dan kerendahan hati. ${ }^{37}$ Seorang pelayan Tuhan adalah seorang pelayan yang bukan hanya menyandang gelar sebagai seorang pelayan. Melainkan seorang yang memahami arti dan hakikat pelayan itu sendiri. ${ }^{38}$ Seorang pelayan Kristus harus benarbenar mempengaruhi bidang pelayanan ini dengan spiritualitasnya. Pelayanan yang penuh dengan kesabaran, kemurahan dan kesetiaan. ${ }^{39}$ Melayani karena sudah mengalami perjumpaan dengan Allah, melayani dengan cinta kepada Tuhan dan juga melayani dengan tidak menyerah pada tantangan. Agar para pelayan bisa melayani dengan baik, para pelayan Tuhan harus membangun hubungan yang baik dengan Tuhan. Memiliki kehidupan rohani yang baik dan terus bertumbuh adalah bagian penting bagi seorang hamba Tuhan. Alasan mengapa kehidupan rohani yang bertumbuh itu penting bagi gembala sidang ialah karena hamba Tuhan adalah seorang pemimpin rohani. Sebagai pemimpin rohani ia adalah pribadi yang menjadi panutan bagi jemaat yang dipimpinnya. ${ }^{40}$

Spiritualitas mempunyai akar pada keteladanan Yesus, yaitu ketaatan yang total kepada Allah dan kepedulian yang eksistensial kepada manusia. Perlu pembinaan warga gereja sehingga mereka memperoleh dewasa penuh atau menjadi orang sempurna terus

37 Asih Rachmani Endang Sumiwi, "Konsep Pelayan Tuhan Perjanjian Baru dan Penerapannya Pada Masa Kini," Epigraphe, 3, No. 2 (2019): 94-104, https://doi.org/10.33991/epigraphe.v3i2.129.

38 Wilson Bawamenewi, "Spiritualitas Seorang Pelayan Tuhan," Eresi, 1, No. 1 (2020): 61-66.

39 David Eko Setiawan \& Anton Ishariyono, "Hakikat Spiritualitas Pelayanan Kristus dan Implikasinya bagi Hamba Tuhan Masa Kini," 2, no. 2 (2020): 116-28.

40 Alfius Areng Mutak, "Reposisi Hati: Memahami Panggilan dan Dinamika Spiritualitas Hamba Tuhan," Sola Gratia: Jurnal Teologi Biblika dan Praktika 2, No. 1 (2014): 46-65.

24 | Excelsis Deo: Jurnal Teologi, Misiologi dan Pendidikan berkelanjutan sampai pada kepenuhan Kristus. ${ }^{41}$ Setiap anggota jemaat bertumbuh bukan untuk dirinya sendiri, tetapi pertumbuhan jemaat sebagai tubuh Kristus, pertumbuhan tersebut ditentukan oleh kebersamaan iman, pemahaman tentang karya Kristus dan kedewasaan rohani dalam merencanakan, berbuat dan bertanggung jawab di hadapan Tuhan. $^{42}$ Pelayanan penggembalaan akan menjadi efektif ketika gembala dapat mengenal dan mengetahui kebutuhan jemaat, sehingga mampu mendisain pelayanan penggembalaan secara tepat dan relevan. Pelayanan demikian akan meningkatkan kepuasan jemaat atas layanan gereja dan mendorong serta meningkatkan loyalitas jemaat kepada gereja. ${ }^{43}$

Dengan demikian gembala sidang sebagai pemimpin rohani dan pembimbing warga jemaat sangat esensial untuk hadir di antara komunitas orang percaya dalam mengarahkan, membimbing dan menuntun untuk mewujudkan tujuan Kristus bagi umatNya, yaitu menjadi pribadi yang seperti Yesus Kristus.

\section{Kedewasaan Rohani Jemaat}

Gembala sidang sebagai pemimpin gereja memiliki tanggungjawab untuk mewujudkan kedewasaan rohani jemaat. ${ }^{44}$ Maka kehidupan rohani atau spiritualitas adalah sikap hidup yang mengandalkan kekuatan Roh Allah dan Roh Kudus dalam diri

${ }^{41}$ Kallistos Ware, The Power of the Name: The Jesus Prayer in Orthodox Spirituality (Fairacres Oxford: SLG Press, 1986).

42 Felipus Nubatonis, “ Pentingnya Kepemimpinan Jemaat dan Motivasi dalam Pelayanan untuk Kedewasaan Rohani Jemaat," Voice of HAMI: 3, no. 2 (2021): 67-84.

43 Mikha Agus Widiyanto \& Susanto, "Pengaruh Pelayanan Kunjungan Pastoral terhadap Pertumbuhan Rohani Jemaat," Evangelikal: Jurnal Teologi Injili dan Pembinaan Warga Jemaat 4, No. 1 (2020): 39-46, https://doi.org/10.46445/ejti.v4i1.214. 44 lbid., 39. 
orang percaya supaya bertumbuh menjadi citra Allah yang semakin sesuai dengan cita-cita sang Pencipta. Roh mendorong setiap orang beriman dan memampukan-nya untuk mencapai tahap kedewasaan-nya dalam Kristus. $^{45}$ Kedewasaan rohani didalam menerangkan kebenaran Firman Allah serta taat kepada perintah dan kehendak Allah. Menurut Felipus Nubatonis menjelaskan bahwa: Kedewasaan Kristen ialah suatu yang harus diperjuangkan setiap saat. Kedewasaan iman diukur dengan Firman Tuhan. " sampai seseorang telah mencapai kesatuan iman dan pengetahuan yang benar tentang Anak Allah, kedewasaan penuh, dan tingkat pertumbuhan yang sesuai dengan kepenuhan Kristus, sehingga kita bukan lagi anak- anak, yang diombang-ambingkan oleh rupa-rupa angin pengajaran, oleh permainan palsu manusia dalam kelicikan mereka yang menyesatkan, tetapi dengan teguh berpegang kepada kebenaran didalam kasih bertumbuh di dalam segala hal ke arah Dia, Kristus, yang adalah Kepala" (bdk. Ef. 4:13-15). ${ }^{46}$

\section{KESIMPULAN}

Pembinaan warga gereja adalah tanggung jawab sepenuhnya gembala sidang sebagai pemimpin rohani bagi jemaat Tuhan. Kedewasaan rohani warga gereja berpengaruh besar dari gembala sidang, maka pelayanan gembala sidang dalam memimpin, membina, mengarahkan, dan menuntun warga jemaat harus penuh dengan kesabaran, kemurahan dan kesetiaan. Yesus memberikan teladan bagaimana menjadi seorang gembala yang baik di mana gembala yang baik adalah gembala yang merawat atau memelihara kawanan domba dengan sepenuh hati bahkan rela mengorbankan nyawa-Nya demi domba

\footnotetext{
45 lbid., 77.

46 lbid., 76.

47 Sarah Andrianti, "Pendidikan Kristen: Keseimbangan antara Intelektualitas dan
}

Gembala sidang dengan warga jemaat menjadi harus selalu sinergy untuk membuat kehidupan setiap pribadi bertumbuh dalam kehidupan rohani. Gereja dalam konteks ini gembala sidang memegang peranan penting untuk meningkatkan kualitas pelayanan kunjungan dalam membimbing dan menuntun jemaat bertumbuh dalam Kristus. Maka spiritualitas orang beriman berhubungan dengan hidup beriman yang mendorong atau memotivasi dan bagaimana seseorang mendapatkan pertolongan dan daya tahan dan semangat hidup untuk mencapai kesempurnaan sesuai dengan kebenaran Alkitab. ${ }^{47}$ Spiritual berkaitan dengan iman seseorang yang dengan dorongan Roh Kudus melakukan dan menjadi sesuai dengan kehendak-Nya. Spiritual orang beriman adalah berbicara tentang relasi pribadi dengan Tuhan melalui Roh Kudus. ${ }^{48}$ Jadi, Kehidupan rohani orang percaya di letakkan dan di dasarkan oleh iman yang berpusat kepada Yesus Kristus sendiri

dombanya. Tugas pembinaan warga gereja bagi penggembalaan adalah mandat yang dipercayakan oleh Allah untuk dilaksanakan sesuai dengan petunjuk dan ketetapan dari Allah sendiri. Akan tetapi kesatuan dalam kebenaran firman-Nya, dalam keberimanan kepada Kristus dan dalam persekutuan dengan Roh Kudus. Oleh sebab itu di perlukan kedewasaan rohani dan kerendahan hati dalam hidup persekutuan oran percaya. Akhir dari semuanya itu adalah bagimana orang percaya sebagai warga gereja mengalami kedewasaan penuh dalam Kristus dan terus tubuh, jiwa dan roh di dalam Yesus Kristus.

Spiritualitas," Jurnal Antusias 2, No. 2 (2012): 2348.

48 Anthony Coniaris, Philokalia: The Bible of Orthodox Spirituality (Minneapolis: Light \& Life Publising Company, 1998), 34. 


\section{DAFTAR PUSTAKA}

Andrianti menguduskan, Sarah. "Pendidikan Kristen: Keseimbangan antara Intelektualitas dan Spiritualitas." Jurnal Antusias 2, No. 2 (2012): 23-48.

Anthony M. Coniaris. Confronting and Controlling Thoughts According to the Fathers of the Philokalia. Minneapolis: Light and Life Publishing, 2004.

Ariefin, Dwi. "Peran Serta Menjaga Kemajemukan Bangsa Dengan Pembinaan Warga Gereja." PASCA: Jur 15, No. 2 (2019): 33-38.

Bawamenewi, Wilson. "Spiritualitas Seorang Pelayan Tuhan." Eresi: Jurnal Teologi Dan Pendidikan Kristen 1, No. 1 (2020): 61-66.

Buinei, Dorus Dolfinus. "Menerapkan Kualifikasi Kepemimpinan Hamba menurut Injil Markus bagi Gembala Sidang GPdI Wilayah Waropen Barat, Papua." EPIGRAPHE: 4, No. 1 (2020): 18-30.

Chysostom, John. The Christian Priesthood. New York: Vladimir's Seminary Press, 1984.

Confessor, St. Maximus the. The Ascetic Life the Four Centuries on Charity. Longmans: Green and co, 1995.

Coniaris, Anthony. Philokalia: The Bible of Orthodox Spirituality. Minneapolis: Light \& Life Publising Company, 1998. Dwiraharjo, Susanto. "Konstruksi Teologis Gereja Digital : Sebuah Refleksi Biblis Ibadah Online di Masa Pandemi Covid19." Jurnal Epigraphe: 4, No. 1 (2020): $1-17$.

Great, Gregorius The. The Book of Pastoral Rule. New York: Vladimir's Seminary Press, 2007.

Hendi. Formasi Rohani: Fondasi, Purifikasi, \& Deifikasi. Yogyakarta: LeutikaPrio, 2019.

Hadiwitanto, Handi. "Metode Kuantitatif
Dalam Teologi Praktis," GEMA Telogika. 2, No. 1 (2017): 1-22.

Hendi \& Syelin Umur, "Strategi Pelayanan Pastoral bagi Kaum Awam menurut Bapa Gereja Gregorius Agung." Fidei: 3 , No.1 .37-61.

Henny, Lucyana. "Konsep Ibadah yang Benar dalam Alkitab." Excelsis Deo: Jurnal Teologi, Misiologi dan Pendidikan 4, No. 1 (2020): 73-88.

Kallistos Ware. The Power of the Name: The Jesus Prayer in Orthodox Spirituality. Fairacres Oxford: SLG Press, 1986.

Latif, Helen Farida. "Pengaruh Pengajaran dan Persekutuan terhadap Tingkat Pertumbuhan Rohani Anak dan Remaja." Epigraphe: Jurnal Teologi dan Pelayanan Kristiani 1, No. 2 (2017): 119-38.

Lukuhay, Alexander Stevanus. "Analisis Teologis Mengenai Beribadah di Rumah di Tengah Pandemi Covid-19 di Indonesia." Jurnal Visio Dei : Jurnal Teologi Kristen 2, No. 1 (2020): 43-61.

Marbun, Purim. "Strategi dan Model Pembinaan Rohani untuk Pendewasaan Iman Jemaat." Jurnal Ilmiah Religiosity Entity Humanity (JIREH) 2, No. 2 (2020): 151-69. https://doi.org/10.37364/jireh.v2i2.42.

Marlin, Jeny. "Pembinaan Warga Gereja Dewasa menurut Surat Efesus 4: 11-16." Missio Ecclesiae 5, No. 1 (2016): 22-34.

Mutak, Alfius Areng. "Reposisi Hati: Memahami Panggilan dan dinamika Spiritualitas Hamba Tuhan." Sola Gratia: Jurnal Teologi Biblika aan Praktika 2, No. 1 (2014): 46-65.

Nubatonis, Felipus. "Pentingnya Kepemimpinan Jemaat dan Motivasi dalam Pelayanan untuk Kedewasaan Rohani Jemaat ." Voice of HAMI: 3, No. 2 (2021): 67-84. Nugroho, Fibry Jati. "Pendampingan Pastoral Holistik: Sebuah Usulan Konseptual 
Pembinaan Warga Gereja."

Evangelikal: Jurnal Teologi Injili Dan

Pembinaan Warga Jemaat 1, No. 2 (2017): 139-54. https://doi.org/10.46445/ejti.v1i2.71.

Puspito, Indro. "Yesus Sebagai Model Gembala Sejati dan Relasinya terhadap Gembala sebagai Pendidik." Excelsis Deo: 4, No. 2 (2020): 87-107.

Putra, Adi. "Hakikat Pertumbuhan Gereja berdasarkan Kisah Para Rasul 2: 4147." Bia': Jurnal Teologi dan Pendidikan Kristen Kontekstual 3, No. 2 (2020): 262-81.

Sembiring, Ngendam. "Mengatasi Degradasi Moral Melalui Pembinaan Warga Gereja." Illuminate: 1, No. 1 (2018): $22-42$.

Setiawan, David Eko, dan Anton Ishariyono. "Hakikat Spritualitas Pelyanan Kristus dan Implikasi-Nya bagi Hamba Tuhan Masa Kini." Pengarah: Jurnal Teologi Kristen 2, No. 2 (2020): 116-28.

Simanjuntak, Junihot M. "Impilikasi Konsep dan

Desain Kurikulum dalam Tugas Pembinaan Warga Jemaat ."12, No. 2 (2014): 251-72.

Siswanto, Anton. "Hamba Tuhan dan Seni Memberi (Sebuah Tinjauan Biblika Berdasarkan Studi Perjanjian Baru)." Excelsis Deo: 4, No. 1 (2020): 19-34.

Sondopen, Dorce. "Relasi antra Penginjilan dan
Pemuridan untuk Pertumbuhan Gereja." 4, No. 1 (2019): 95-105.

Srisusiani, Susana Endang. "Kajian Teologis Pertumbuhan Rohani dan Kepemimpinan yaang Menghamba berdasarkan Yehezkiel 22:30." Geneva: 2, No. 2 (2020): 83-91.

Sumiwi, Asih Rachmani Endang. "Konsep Pelayan Tuhan Perjanjian Baru dan Penerapannya Pada Masa Kini." Epigraphe: Jurnal Teologi dan Pelayanan Kristiani 3, No. 2 (2019): 94-104.

https://doi.org/10.33991/epigraphe.v3i2 .129 .

Telaumbanua, Arozatulo. "Peran Gembala Sidang Sebagai Pendidik Dalam Pertumbuhan Rohani Jemaat." Fidei: Jurnal Teologi Sistematika Dan Praktika 2, No. 2 (2019): 362-87. https://doi.org/10.34081/fidei.v2i2.45.

Widiyanto, Mikha Agus, and S Susanto. "Pengaruh Pelayanan Kunjungan Pastoral Terhadap Pertumbuhan Rohani Jemaat." Evangelikal: Jurnal Teologi Injili dan Pembinaan Warga Jemaat 4, no. 1 (2020): 39-46. https://doi.org/10.46445/ejti.v4i1.214.

Zega, Sabariah. "Refleksi Teologis tentang Makna Ibadah yang Sejati." Voice of HAMI: Jurnal Teologi dan Pendidikan Agama Kristen 3, No. 1 (2020): 28-38. 
Jurnal Excelsis Deo: Vol. 5, No. 1 Juni 2021 